\title{
Multinational outbreak of Salmonella Enteritidis infection during an international youth ice hockey competition in Riga, Latvia, preliminary report, March and April 2015
}

\author{
A K Pesola (katrinepesola@gmail.com) ${ }^{1}$, T Pärnn ${ }^{1,2}$, S Huusko ${ }^{1}$, J Perevoščikovs ${ }^{3}$, J Ollgren ${ }^{1}$, S Salmenlinna ${ }^{1}$, T Lienemann ${ }^{1}$, \\ C Gossner ${ }^{4}$, N Danielsson 4 , R Rimhanen-Finne ${ }^{1}$ \\ 1. National Institute for Health and Welfare (THL), Department of Infectious Diseases Surveillance and Control, Helsinki, Finland \\ 2. European Programme for Intervention Epidemiology Training (EPIET), European Centre for Disease Prevention and Control \\ (ECDC), Stockholm, Sweden \\ 3. Centre for Disease Prevention and Control of Latvia \\ 4. European Centre for Disease Prevention and Control (ECDC), Stockholm, Sweden
}

Pesola AK, Pärn T, Huusko S, Perevoščikovs J, Ollgren J, Salmenlinna S, Lienemann T, Gossner C, Danielsson N, Rimhanen-Finne R. Multinational outbreak of Salmonella Enteritidis infection during an international youth ice hockey competition in Riga, Latvia, preliminary report, March and April 2015 . Euro Surveill.

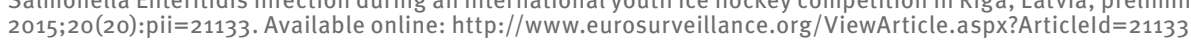

A multinational outbreak of salmonellosis linked to the Riga Cup 2015 junior ice-hockey competition was detected by the Finnish health authorities in mid-April and immediately notified at the European Union level. This prompted an international outbreak investigation supported by the European Centre for Disease Prevention and Control. As of 8 May 2015, seven countries have reported 214 confirmed and suspected cases, among which 122 from Finland. The search for the source of the outbreak is ongoing.

\section{The event}

On 14 April 2015, a general practitioner in a municipal public health authority in Finland notified the National Registry for Food and Waterborne Outbreaks (RYMY) [1] about a cluster of 30 cases of gastrointestinal disease. All had attended the Riga Cup on the 3 to 6 April weekend 2015 and six had laboratory-confirmed Salmonella serogroup D infection.

The Riga Cup is an annual international youth icehockey competition where mainly male teams, with occasional female players, participate. Players in the event are officially categorised in five age groups comprising individuals between 10 and 18 years-old. In 2015, the competition consisted of five tournaments lasting three to four days each, which took place over five consecutive weekends from 27 March to 26 April. The competition attracted 197 teams from Europe, including Belarus, Russia and Ukraine as well as 16 European Union and European Free Trade Association (EU/EFTA) countries. Finland contributed 50 teams. The total number of international and national participants was around 5,000. Tournaments were played according to age groups in four hockey arenas, which were used in parallel, with arena A being the main arena. A fifth arena was added on the last weekend of the tournament. Lunches and dinners for the teams were included in the competition package. The teams, including their male and female coaches and officials, were scheduled to have their meals at the arenas where they were playing. Breakfasts were taken at the hotels where the teams stayed.

\section{Epidemiological and microbiological investigations in Finland}

Following the notification of the first cluster of cases in mid-April, the Finnish National Institute for Health and Welfare (THL) monitored notifications reported to the National Infectious Disease Registry (NIDR) in order to capture Salmonella infections with a travel history to Latvia. Names were cross-checked against a list of the Finnish players in the Riga Cup obtained from the tournament website. Other cases of Salmonella sp. in NIDR with travel history to Latvia were contacted to determine whether they had participated in the tournament as an accompanying family member or official. Cases were identified according to the outbreak case definition (box).

Since this led to the finding of other possible clusters in different parts of Finland, THL invited on 21 April, the Finnish clubs participating in the Riga Cup 2015 to an online survey in order to describe and determine the magnitude of the outbreak. This survey asked about demographics, dates of participation in the competition and place of accommodation. Further, the respondents were requested to specify the tournament venues where they had eaten and on which dates, along with a description of what had been consumed. It was also 


\section{Box}

Finnish case definition, multinational outbreak of Salmonella Enteritidis infection during an international youth ice hockey tournament in Riga, Latvia, March-April 2015

A confirmed case: any person with laboratory-confirmed infection with Salmonella sp. having participated in the Riga Cup 2015 between 27 March and 26 April 2015 and having had onset of diarrhoea with three or more loose stools a day on or after 27 March.

A suspected case: any person having participated in the Riga Cup 2015 between 27 March and 26 April 2015 and having had an onset of diarrhoea on or after 27 March.

enquired whether any foods and beverages had been taken outside the venues. Date of onset of diarrhoea with three or more loose stools a day, fever $\left(\geq 38^{\circ} \mathrm{C}\right)$, headache, nausea, vomiting, or stomach ache were questioned as were any possible hospitalisations.

As of 8 May, 65 persons with Salmonella sp. infection, who had participated as players or officials in the Riga Cup 2015 between 27 March and 26 April 2015 and had onset of symptoms on or after 27 March were identified by the NIDR in Finland. By the same date, 315 persons had also responded to the online survey. Of these, 31 respondents were classified as confirmed, and were among the 65 confirmed cases identified by the NIDR. The survey additionally identified 57 suspected cases.

Of the 88 cases identified in the survey (Figure), 78 $(87 \%)$ were male, the median age was 13 years (range: 8-66 years), 7 (8\%) had been hospitalised, 86/87 (99\%) had been playing at arena A and 39/88 (44\%) participated during the tournament taking place over the second weekend of the competition.

Nine patient isolates were microbiologically characterised [2-4] at THL. The isolates were selected so that they represented clusters identified in different participating teams from different parts of Finland (Figure). All nine cases had been infected by $S$. Enteritidis phage type 1 (PT1) with multilocus variable-number tandem repeat analysis (MLVA) profile 3-10-6-4-1 (SENTR7SENTR5-SENTR6-SENTR4-SE3). The isolates were susceptible to the standard panel of antibiotics tested (ampicillin, cefotaxime, chloramphenicol, gentamicin, mecillinam, meropenem, nalidixic acid, perfloxacin, streptomycin, sulfonamide, tetracycline, and trimethoprim). S. Enteritidis $\mathrm{PT}_{1}$ is rare in Finland as well as in Norway and Sweden (Lin Thorstensen Brandahl and Cecilia Jernberg, personal communications, May 2015), but common in Baltic countries, Russia and Korea [5,6].

\section{International investigations}

On 16 April, THL launched an urgent inquiry through the Epidemic Intelligence Information System for Food and Waterborne Diseases (EPIS-FWD) [7] to identify cases in other countries. Potentially affected nonEU countries were informed of the outbreak via the World Health Organization and were given access to EPIS-FWD.

On 24 April, a Rapid Risk Assessment of the outbreak by the European Centre for Disease Control and Prevention (ECDC) [8] was distributed through the Early Warning and Response System (EWRS). On the request from Latvia, ECDC deployed a fellow from the European Programme for Intervention Epidemiology Training (EPIET) from Finland to support the investigation in Riga on 26 April 2015.

On 29 April, the Latvian Centre for Disease Prevention and Control (LCDC) contacted the leaders of all teams participating in the Riga Cup, except the Finnish and Norwegian teams, which had already been contacted by their national public health authorities, by email and asked if they were aware of cases of gastroenteritis with onset during or after the tournament.

An ECDC expert on food and waterborne disease outbreaks joined the investigating team in Riga on 4 May 2015. As of 8 May, seven countries (Estonia, Finland, Hungary, Lithuania, Norway, Sweden, and the United Kingdom (UK)) have reported a total of 214 cases with gastrointestinal symptoms. Identical MLVA profiles to the Finnish cases were confirmed in one Norwegian and three Swedish patient isolates. The MLVAs were performed at the Department of Food-borne Infections at the Norwegian Institute of Public Health, and Public Health Agency of Sweden, respectively. The results were communicated through EPIS and at telephone conferences concerning the outbreak (Lin Thorstensen Brandahl and Cecilia Jernberg, personal communications, May 2015).

\section{Food and environmental investigations in Latvia}

Based on the information gained from the first detected cluster in Finland, the cafeteria at arena A was suspected as the source of outbreak [8]. On 16 April, the THL and the Finnish Food Safety Authority, Evira, alerted their respective counterparts in Latvia through the EWRS [9] and the Rapid Alert System for Food and Feed [10]. On the same day, the LCDC in collaboration with the Latvian Food and Veterinary services inspected the kitchen at arena $A$, interviewed all kitchen staff and their family doctors, and collected faecal samples and environmental and food samples. None of the kitchen staff reported gastrointestinal symptoms during the Riga Cup and all the samples were negative for $S$. Enteritidis. No cases of $S$. Enteritidis related to Riga Cup were registered in Latvia and the number of $S$. Enteritidis cases did not exceed the average level in March and April 2015.

Follow-up controls took place at arena A on 24 and 27 April. Members of one team playing at the tournament 
Number of cases by date of onset of diarrhoea among participants attending an international youth ice hockey competition in Riga, Latvia, March-April $2015(\mathrm{n}=88)$

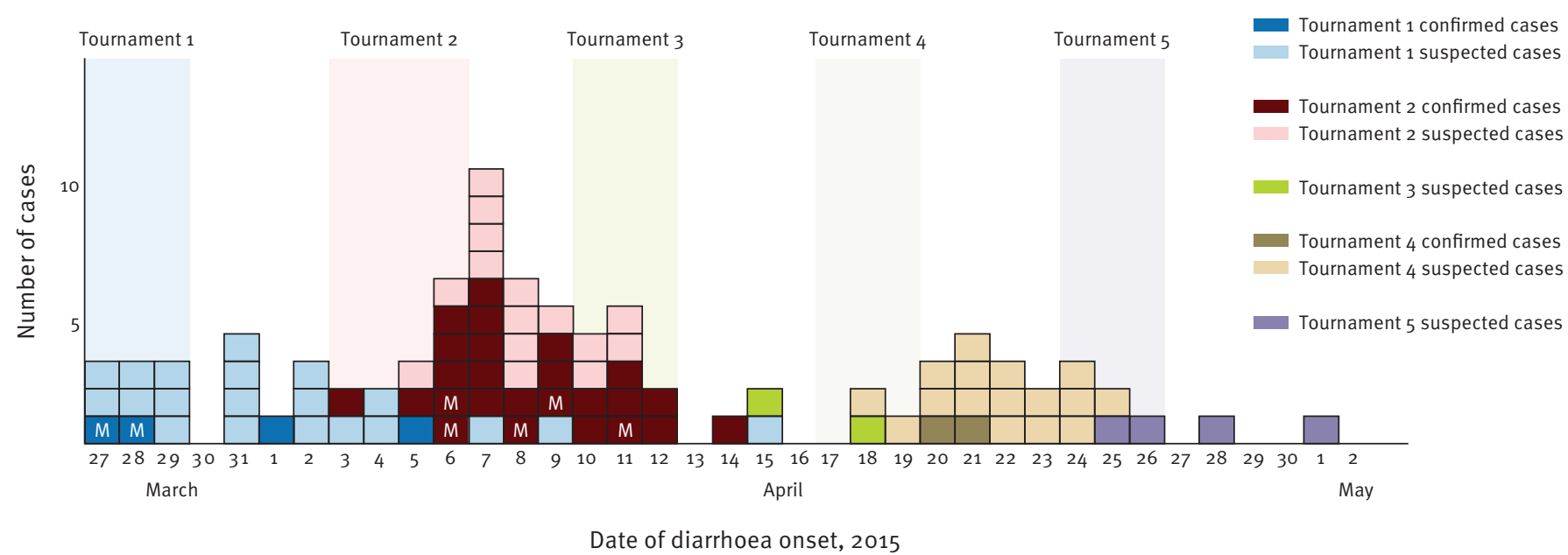

MLVA: multilocus variable-number tandem repeat analysis

The letter $M$ indicates cases that participated in the online survey related to the Finnish epidemiological investigation, and whose isolates were microbiologically characterised by MLVA.

on the second weekend of the competition, with five suspected cases, had only eaten their meals in arena $B$, so arena B was inspected on 29 April. Menus were retrieved from all arenas and wholesale suppliers were identified via the purchase receipts. The arena restaurants had been contracted by the organiser and advised to serve the same lunch and dinner menus to the participating teams. The meals were mainly prepared at the tournament arenas. The caterers at the venues served the team members a separate menu than the public during the weeks in between the tournament weekends. Leftovers of the food served to the teams were discarded at the end of each day. Latvian teams did not take lunch and dinner at the venues.

\section{Control measures}

Physicians in Finland were alerted about the outbreak by news bulletins (on 15, 20 and 30 April) [11]. The Finnish ice-hockey teams scheduled to play on the last tournament weekend were prior advised to take standard hand hygiene and food safety precautions, such as eating only cooked foods and drinking bottled beverages.

In Latvia, two other junior ice hockey events took place in Riga, from 28 April to 2 May 2015 and from 14 to 16 May 2015 respectively. As some Finnish teams were to take part in these two events, the Finnish public health authorities informed these teams and the Finnish Ice Hockey Association on 27 April about the Riga Cup outbreak and ongoing investigation. Standard hand hygiene and food safety precautions were recommended and participants were also advised to notify THL in case gastrointestinal symptoms appeared during or after the competition.
On 30 April and 8 May the Latvian public health authorities contacted the organisers of both events and recommended to consume only well-cooked foods and maintain proper hand hygiene. In addition, a phone number to a specialist from the Latvian public health authority was provided in case any of the event participants would develop gastroenteritis symptoms.

\section{Conclusions}

This outbreak was first detected by municipal public health authorities in Finland. Due to budget cuts at THL since 2015 Salmonella isolates of foreign origin are no longer typed nor are the cases monitored in real time and outbreaks of foreign origin can only be identified at a local level. This will delay detection of Salmonella outbreaks among travellers. Cross-border outbreaks and outbreaks related to mass gatherings pose special problems [12-15] and cooperation between national authorities and ECDC is needed. The investigation to determine the source of the outbreak is ongoing and a retrospective cohort study among event participants from several EU/EFTA countries is underway in order to identify the source.

\section{Acknowledgments}

We would like to thank experts from THL, The Centre for Disease Prevention and Control of Latvia, Latvian Food and Veterinary Services, national focal points of affected countries and ECDC which are continuously contributing to the outbreak investigation.

\section{Conflict of interest}

None declared. 


\section{Authors' contributions}

Anne-Katrine Pesola, Triin Pärn, Sari Huusko, Jurijs Perevoščikovs, Jukka Ollgren, Saara Salmenlinna, Taru Lienemann, Celine M. Gossner, Niklas Danielsson and Ruska Rimhanen-Finne reviewed and approved the manuscript. Anne-Katrine Pesola acted as outbreak coordinator, AnneKatrine Pesola, Triin Pärn, Sari Huusko, Jurijs Perevoščikovs, Jukka Ollgren, Celine M. Gossner, Niklas Danielsson and Ruska Rimhanen-Finne carried out the epidemiological in vestigation. Saara Salmenlinna and Taru Lienemann, carried out the microbiological investigation, Anne-Katrine Pesola, Triin Pärn and Ruska Rimhanen-Finne drafted the manuscript and data analysis. All co-authors critically reviewed the draft of the paper and approved the final version.

\section{References}

1. Finnish food Safety Authority Evira. Elintarvike- ja vesivälitteisten ruokamyrkytysepidemioiden ilmoittaminen ja raportointi. [Food and waterborne outbreaks, notification and reporting]. Finland; 2014. Finnish. Available from: http://www. evira.fi/portal/fi/tietoa+evirasta/asiointi/sahkoinen+asiointi/ elintarvikkeet/ruokamyrkytysepidemioiden+raportointi+rymy/

2. Issenhuth-Jeanjean S, Roggentin P, Mikoleit M, Guibourdenche $M$, de Pinna E, Nair S, et al. Supplement 2008-2010 (no. 48) to the White-Kauffmann-Le Minor scheme. Res Microbiol. 2014;165(7):526-30. http://dx.doi.org/10.1016/j. resmic.2014.07.004 PMID:25049166

3. Ward LR, de Sa JD, Rowe B. A phage-typing scheme for Salmonella enteritidis. Epidemiol Infect. 1987;99(2):291-4. http://dx.doi.org/10.1017/So950268800067765 PMID:3315705

4. Hopkins KL, Peters TM, de Pinna E, Wain J. Standardisation of multilocus variable-number tandem-repeat analysis (MLVA) for subtyping of Salmonella enterica serovar Enteritidis. Euro Surveill. 2011;16(32):19942. PMID:21871223

5. Hasenson LB, Kaftyreva L, László VG, Woitenkova E, Nesterova M. Epidemiological and microbiological data on Salmonella enteritidis. Acta Microbiol Hung. 1992;39(1):31-9. PMID:1632197

6. Kang ZW, Jung JH, Kim SH, Lee BK, Lee DY, Kim YJ, et al. Genotypic and phenotypic diversity of Salmonella enteritidis isolated from chickens and humans in Korea. J Vet Med Sci. 2009;71(11):1433-8. http://dx.doi.org/10.1292/jvms.001433 PMID:19959892

7. Gossner CM, de Jong B, Hoebe CJPA, Coulombier D, and European Food and Waterborne Diseases Study Group. Event-based surveillance of food-and waterborne diseases in Europe: A six-year review of urgent inquiries, 2008-2013. Euro Surveill. Forthcoming.

8. European Centre for Disease Prevention and Control (ECDC) Multinational outbreak of Salmonella Enteritidis infections among junior ice hockey players attending the Riga Cup 2015 - 27 April 2015. Stockholm: ECDC; 2015. Available from: http:// ecdc.europa.eu/en/publications/Publications/SalmonellaNorway-Latvia-Finland-rapid-risk-assessment.pdf

9. European Commission. Commission decision 2009/547/EC of 10 July 2009 amending Decision 2000/57/EC on the early warning and response system for the prevention and control of communicable diseases under Decision No 2119/98/EC of the European Parliament and of the Council. Official Journal of the European Union. Luxembourg: Publications Office of the European Union. 14.7.2009: L 181/57. Available from: http:// eur-lex.europa.eu/LexUriServ/LexUriServ.do?uri=0J:L:2009:18 1:0057:0060:EN:PDF

10. European Commission. Regulation (EC) No $178 / 2002$ of the European Parliament and of the Council of 28 January 2002 laying down the general principles and requirements of food law, establishing the European Food Safety Authority and laying down procedures in matters of food safety. Official Journal of the European Union. Luxembourg: Publications Office of the European Union, 1.2.2002: L 31/1. Available from: http://eur-lex.europa.eu/LexUriServ/LexUriServ.do?uri=0J:L:2 002:031:0001:0024:EN:PDF

11. Finnish National Institute for Health and Welfare (THL). Several junior hockey players at Riga Cup in Latvia contract salmonella. Finland. Helsinki: TFL; 2015. Available from: https://www.thl.fi/en/web/thlfi-en/-/several-junior-hockeyplayers-at-riga-cup-in-latvia-contract-salmonella? redirect=htt ps\%3A\%2F\%2Fwww.thl.fi\%2Fen\%2Fweb\%2Fthlfi-en\%2Fmainpage\%3Fp_p_id\%3D101_INSTANCE_Hqr7tiXohzzV\%26p_p_ lifecycle\%3Do\%26p p state\%3Dnormal\%26p p mode $\% 3$ Dview $\% 26 p$ p col id $\% 3$ Dcolumn-2-1-3\%26p p col pos\%3D1\%26p_p_col_count \%3D2
12. Rebolledo J, Garvey P, Ryan A, O’Donnell J, Cormican M, Jackson $\mathrm{S}$, et al. International outbreak investigation of Salmonella Heidelberg associated with in-flight catering. Epidemiol Infect. 2014;142(4):833-42. http://dx.doi. org/10.1017/So950268813001714 PMID:23890227

13. Inns T, Lane C, Peters T, Dallman T, Chatt C, McFarland N, et al.; Outbreak Control Team. A multi-country Salmonella Enteritidis phage type $14 \mathrm{~b}$ outbreak associated with eggs from a German producer: near real-time application of whole genome sequencing and food chain investigations, United Kingdom, May to September 2014. Euro Surveill. 2015;20(16):21098. PMID:25953273

14. Camps N, Domínguez A, Company M, Pérez M, Pardos J, Llobet T, et al.; Working Group for the Investigation of the Outbreak of Salmonellosis in Torroella de Montgri. A foodborne outbreak of Salmonella infection due to overproduction of egg-containing foods for a festival. Epidemiol Infect. 2005;133(5):817-22. http://dx.doi.org/10.1017/So950268805004504 PMID:16181500

15. Botelho-Nevers E, Gautret P. Outbreaks associated to large open air festivals, including music festivals, 1980 to 2012. Euro Surveill. 2013;18(11):20426. PMID:23517872 